\title{
CONTRIBUIÇÃO DE HORST RITTEL PARA A ABORDAGEM CIENTÍFICA AO PROJECTO NO INÍCIO DA ERA COMPUTACIONAL
}

\section{THE CONTRIBUTION OF HORST RITTEL TO THE SCIENTIFIC APPROACH TO DESIGN IN THE BEGINNING OF THE COMPUTATIONAL ERA}

\author{
Isabel Clara Neves 1 \\ Faculdade de Arquitectura da Universidade de Lisboa, Lisboa, Portugal, isaclaraneves@fa.ulisboa.pt
}

\section{Resumo}

Este artigo desenvolve uma análise sobre parte do contexto cultural e tecnológico que contribuiu para o surgimento do pensamento e prática computacional na arquitectura. Pretende-se questionar e demonstrar a relevância da contribuição de Horst Rittel para a abordagem científica ao Projecto no início da era computacional, durante a sua colaboração como professor na Hochschule für Gestaltung - Ulm, Alemanha, no contexto da análise de métodos científicos associados ao projecto, ainda sem a utilização de computadores. Argumenta-se que nesta Escola, através das ideias desenvolvidas por professores tal como Horst Rittel, criaram-se fundamentos que estão na base das posteriores abordagens computacionais na arquitectura, as quais mais tarde vieram a utilizar a computação não como uma ferramenta de desenho geométrico, mas sim como uma ferramenta de desenho computacional. Algumas destas matérias viriam a ser investigadas e ampliadas anos depois em centros de investigação académicos de departamentos de Arquitectura e Design. Para dar resposta à questão levantada durante a investigação do presente artigo, procedeu-se à análise do material da biblioteca da Escola, encerrada em 1968, que se encontra armazenado no Arquivo e Museu da HfG-Ulm, sendo que a recolha de material original das aulas das disciplinas científicas que Horst Rittel leccionava, proveniente desse Arquivo, foi o eixo metodológico fulcral do presente trabalho. Esta investigação contribuiu assim para clarificar alguns territórios não tão investigados, servindo esta de complemento a uma série de outras investigações que analisam as relações e sinergias entre protagonistas e instituições, que conformaram uma perspectiva computacional na arquitetura nos anos 60. Finalmente, este artigo contribuiu assim para cartografar e estudar o papel do matemático e investigador Horst Rittel, suas ideias distintivas, pelo modo como definiram uma nova abordagem ao projecto, marcadamente influenciada por métodos científicos.

Palavras-Chave Hochschule für Gestaltung of Ulm. Horst Rittel. Metodologia científica. Design Computacional.

\begin{abstract}
This paper goes back fifty years to a period that can be considered the birth of the computational design research. During the sixties the computer was only accessible to a few mathematicians or programmers and it becomes object of a much wider theorization and influence. Calculus and mathematical logic inherent to the computer support the emergence of areas including the information theory and the operational research, which would call the attention of social science and arts. Some Design and Architecture Research Centers, in the UK and the USA start using the computer to support design methodologies based on analysis and mathematical logic as well as to assist the design conception process. A similar approach can also be found at he Hochschule für Gestaltung Ulm (HfG-UIm), in Germany, founded in 1953 by the Swiss architect Max Bill. Despite its short existence, it was considered a very important school in the twentieth century, where a remarkable group of teachers and ideas converged. In this context, this paper describes the relevance of the HfG UIm regarding the exploration of scientific analysis methods associated with the Design Process. Comparing to other contemporary Research Centers, this approach at the HfG UIm was remarkable because it was introduced and practiced without the use of computers. Therefore, this paper dedicate its attention to tracing, analyzing and illustrating the particular contribution of Horst Rittel, based on the manuscripts used at the HfG-UIm classes. Being a mathematician, his integration in the design curriculum was innovative and resulted in the development of a scientific methodology in design. This article thoroughly demonstrate that the work developed by some teachers, like Horst Rittel launched the foundations that constitute the basis for further computational approaches in architecture.
\end{abstract}

Keywords:: HfG - Hochschule für Gestaltung Ulm. Horst Rittel. Scientific Methodolog. Computational Design.

How to cite this article:

NEVES, Isabel Clara. Contribuição de Horst Rittel para a abordagem científica ao projecto no início da era computacional. PARC Pesquisa em Arquitetura e Construção, Campinas, v. 6, n. 1, p. 39-55, jan./mar. 2015. ISSN 1980-6809 


\section{Introdução}

Hoje em dia o uso de metodologias de design computacional é uma tendência comum no ensino e na prática da arquitectura. No entanto, os objectivos e o âmbito de tais abordagens podem ser muito diversos. Enquanto algumas abordagens percebem e encaram o computador como um complemento de ferramentas, outras estão comprometidas com a exploração de caminhos que estimulam a revisão das teorias e possibilidades de design para a disciplina de arquitectura. Esta procura reiterada da inovação implica um profundo entendimento não só das técnicas de design digital, mas também de um pensamento computacional crítico para orientar a sua aplicação à prática. Um enquadramento conveniente da história da tecnologia na arquitectura é então importante para formular as possibilidades de uma "continuidade digital" ou "revolução na disciplina". Assim, torna-se pertinente elaborar uma análise de um período que pode ser considerado como o início da fundação de uma perspectiva de design computacional na arquitectura, e que corresponde à década de 60. Partese de duas constatações iniciais a partir das quais se desenvolveu a investigação. A primeira está relacionada com o facto de, hoje em dia, a utilização de tecnologias digitais em arquitectura ser uma prática generalizada que se encontra a recuperar um conjunto de teorias e conceitos ligados à computação, desenvolvidos durantes os anos 60. A segunda constatação relacionase com o início e desenvolvimento de uma abordagem científica aos métodos de design, que ocorreu na mesma época, e foi marcado pelo interesse em princípios e metodologias científicas aplicadas à arquitectura e ao planeamento que, com o auxílio do computador, foram desenvolvidas em centros de investigação pioneiros situados sobretudo nos EUA e no Reino Unido, tais como o Land Use and Built Form Studies Center (LUBFS), fundado em Cambridge; o Design Methods Movement no Royal College of Art; o Architecture Group Machine, no Massachusetts Institute of Technology (MIT); o Design Methods Group (DMG), no College of Environmental Design em Berkeley; o Centre for ConFigurational Studies, na Open University em Milton Keynes, Reino Unido; e também o Design Research Center (DRC), na Carnegie Mellon, EUA; o The Institute for Architecture and Urban Studies (IAUS), onde começam a integrar-se as metodologias de desenho baseadas na análise e lógica matemática e na sua aplicação no processo de concepção de projecto (Figura 1 e Figura 2).

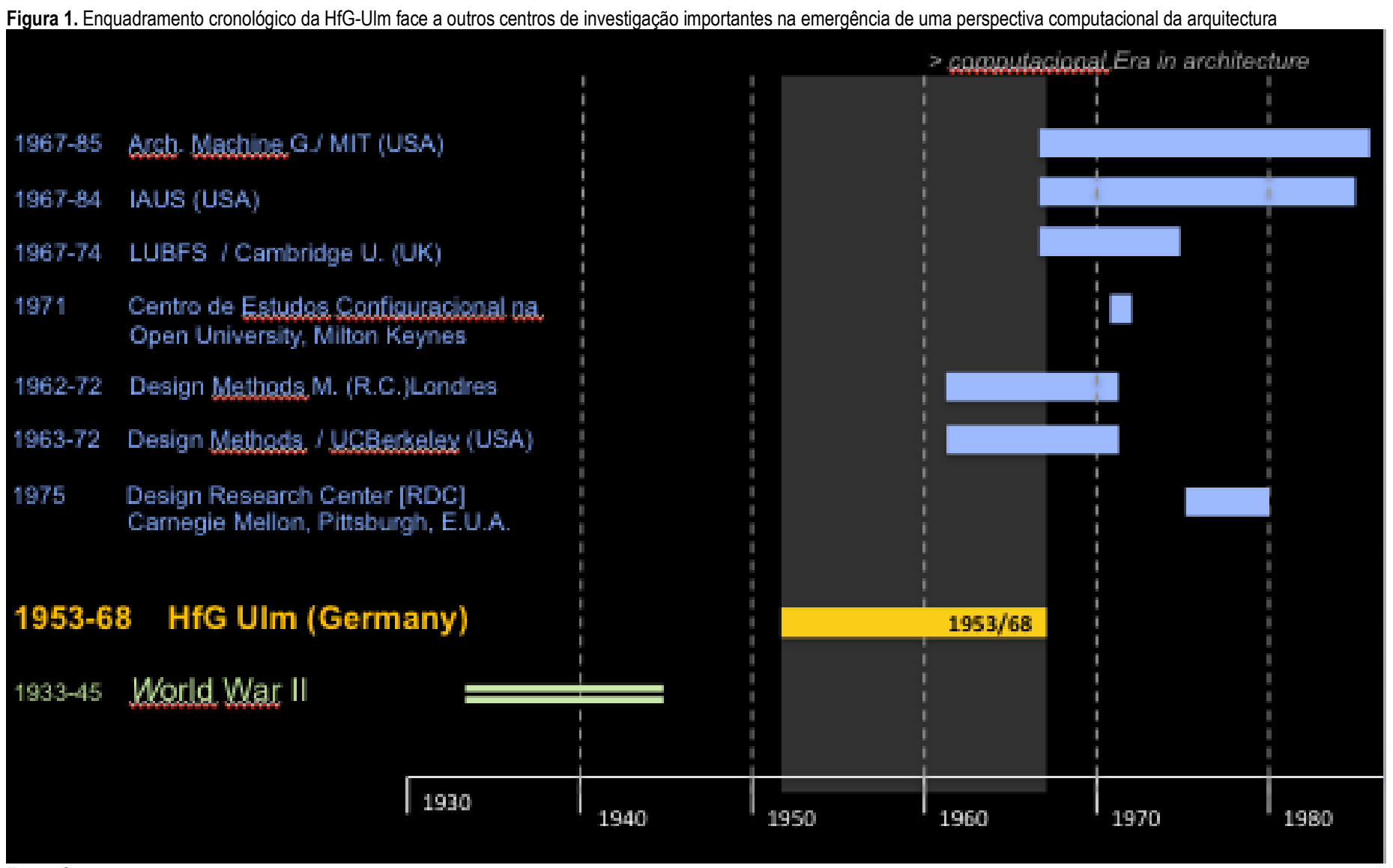

Fonte: Os autores 
Figura 2. Esquema das ligações dos Protagonistas dos principais Centros de Investigação de Arquitectura e Computação durante os anos 60 e 70 , entre a Europa e os Estados Unidos. UC Berkeley-University of California, Berkeley (San Francisco); UCLA-University of California, Los Angeles; RAND - Reasearch and National Development (Santa Monica) Los Angeles; Harvard - Harvard University, Cambridge (Boston); Massachusetts Institute of Technology: MIT, Architecture Machine Group Cambridge (Boston); CMU-DRC Carnegie Mellon University, Design Research Center, Pittsburgh; LUBFS - Cambridge The Land Use and Built Studies, University of Cambridge; M. Keynes The Center for ConFigurational Studies at the Open University, Milton Keynes; Royal College of Arts

Estados Unidos da América

Reino Unido

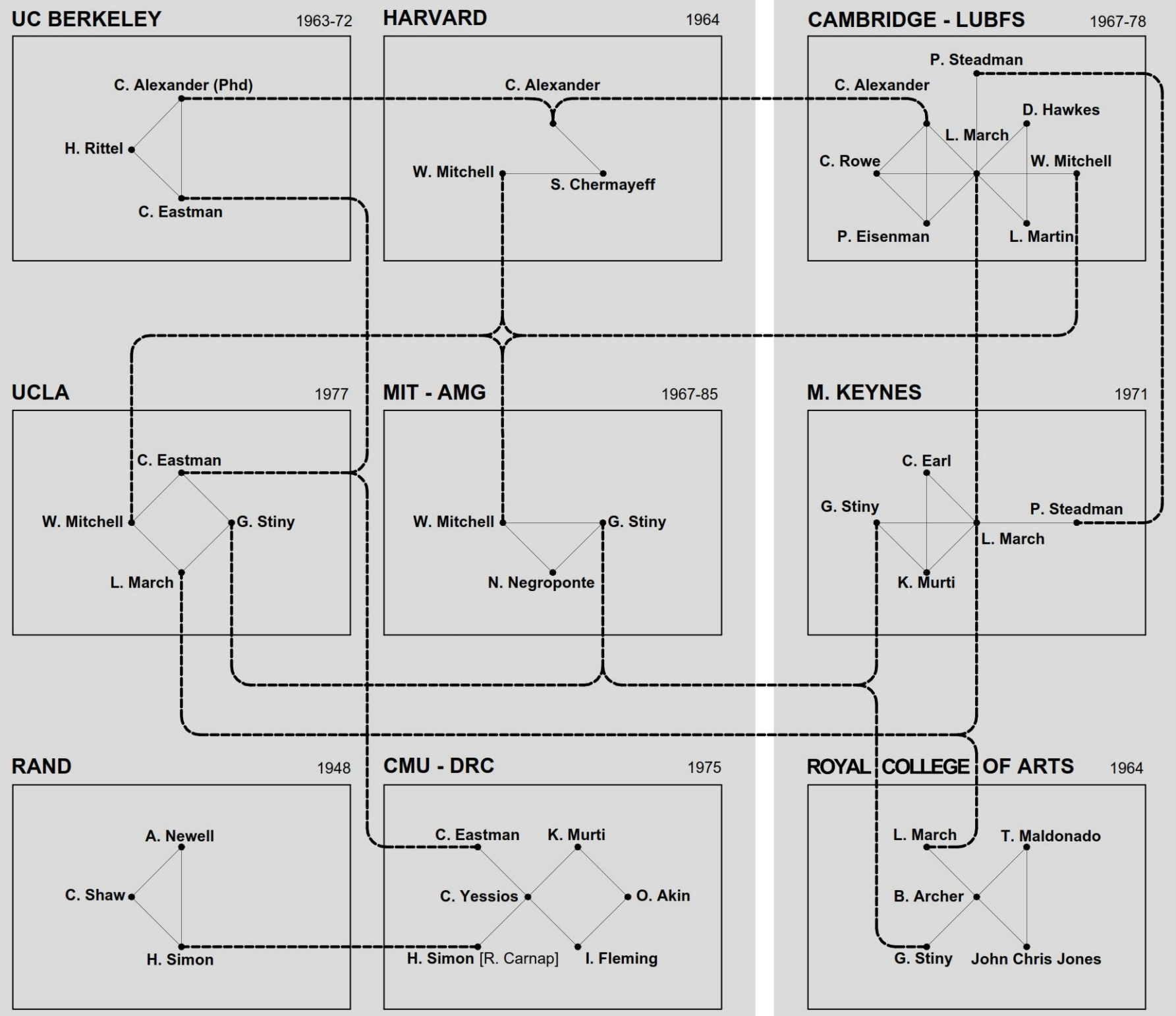

Fonte: Os autores

Não obstante, esta motivação esteve também presente no contexto alemão, uma década antes, na HfG-Ulm, sem o auxílio dos computadores. Este artigo traça a contribuição da HfG-Ulm, não muito estudada, na introdução da computação no projecto arquitectónico, uma das condições mais visíveis que ganharam relevância nesta Escola - Horst Rittel e o seu projecto de Metodologia Científica. Concluiu-se que se criaram fundamentos que estão na base das posteriores abordagens computacionais na arquitectura, as quais mais tarde vieram a utilizar a computação não como uma ferramenta de desenho geométrico, mas sim como uma ferramenta de desenho computacional. Algumas destas matérias viriam a ser investigadas e ampliadas anos depois em centros de investigação académicos de departamentos de Arquitectura e Design. 


\section{HfG Ulm - O Projecto Educacional}

A HfG-Ulm, na Alemanha, funcionou de 1953 até 1968 e durou a transição da sociedade industrial para a sociedade pós-industrial. Apesar da sua curta existência, a HfG-Ulm representou o projeto contínuo de Pós-Guerra de repensar o papel da ciência social dentro de uma fé na supremacia da razão. A sua missão de investigação do "bom design" afirmou-se como um projecto moral com uma firme crença na estética como sinal de uma sociedade democrática, devido à história pessoal dos seus fundadores, da era de Resistência nazista. Num dos seus textos críticos referentes à contribuição do HfG, Kenneth Frampton afirma que havia pouca dúvida de que a HfG tinha sido a escola mais significativa do projecto a entrar em vigor desde o final da Segunda Guerra Mundial, não tanto pelo que ela alcançou em termos de produção real, nem pelo grande número de designers que efectivamente tinha formado, mas finalmente, pelo seu alto nível extraordinário de consciência crítica que conseguiu sustentar no seu trabalho quotidiano (FRAMPTON, 1974 apud FRAMPTON, 2002).

Este projecto educativo, apesar de não ter sido exaustivamente estudado teve, no entanto, resultados tanto a nível prático, através da colaboração com várias empresas, como a nível teórico, tal como é perceptível em revistas em que o resultado do ensino sistemático foi partilhado. A revista Ulm (Figura 3) foi o meio oficial de auto manifestação da HfG com textos produzidos sobretudo por Tomás Maldonado e Gui Bonsiepe, entre outros. Esta pode ser considerada uma das maiores contribuições na projecção da educação nos anos 50 e 60.

Figura 3. Capa da revista de Publicação HfG-Ulm

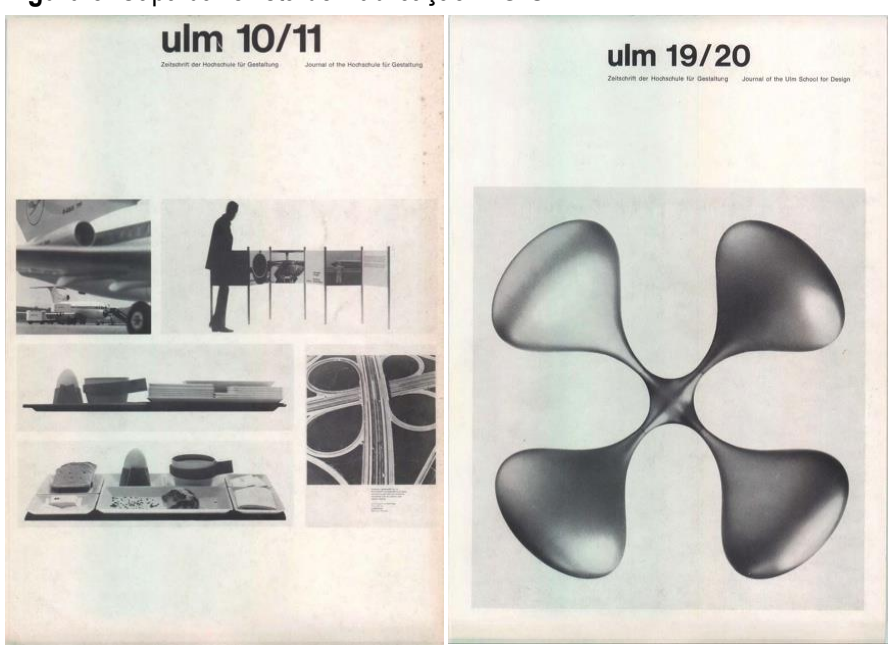

Fonte:http://www.hfgarchiv.ulm.de/english/the_hfg_ulm/

O ensino na HfG-Ulm reconheceu os ideais de padronização e produção em massa, investigando uma abordagem científica que integrava os métodos sistémicos, objectivos de recolha e processamento de dados, a fim de informar a solução de design. Seria sintetizar a ciência e o design num novo humanismo científico que reconheceu o pluralismo de métodos e perspectivas metodológicas necessárias ao designer para enfrentar os novos problemas da cultura industrial. O que surgiu, no entanto, foi o início de uma visão operacional da ciência do design, o que Maldonado chamou de operacionalismo científico. Em nenhum outro lugar esta questão foi focada, só entre os designers da devastação, com curiosidade ilimitada sobre todas as novas disciplinas da ciência e as novas ideias da filosofia da ciência e da matemática (BUCHANAN, 2009, p. 427). Como Maldonado afirmara: "The mainspring of all of our curiosity, our reading, and our theoretical work was our determination to find a solid methodological basis for the work of design" (MALDONADO, 1991, p. 222). Deste modo o conhecimento científico e os novos métodos podiam ser aplicados na procura de solução de problemas de design dentro de um ambiente industrializado.

\section{Horst Rittel na HfG-Ulm}

Consideramos Horst Rittel o principal mentor da metodologia científica da HfG-Ulm, que centrou a sua atenção nos procedimentos de projecto. A formação matemática de Horst Rittel deu-lhe acesso a modelos conceptuais, a que os designers comuns por norma não tinham tido acesso. Introduziu assim métodos de investigação operacional, teoria da decisão matemática, teoria dos jogos, análise de sistemas e técnicas de planeamento e, portanto, enriqueceu o repertório dos métodos de suporte do projecto (KRIPPENDORFF, 2006, p. 311). As complexidades envolvidas nessas tarefas exigiram novas estratégias para a gestão de dados, tomada de decisão e planeamento. Enquanto as abordagens científicas tradicionais estavam interessadas numa solução do problema, a nova ciência da tomada de decisão estava interessada no processo para se alcançar a solução do problema. Em 1958, Horst Rittel entrou na HfG-Ulm. A sua primeira missão, foi a palestra sobre informação e teoria da comunicação, que foi considerada pelos alunos da Escola a chave para o futuro. Segundo Klaus Krippendorff, foi na sua primeira palestra que se apresentaram os detalhes técnicos da teoria de Shannon. Sendo muito mais jovem, mais prático e rápido a adaptar-se às necessidades do currículo da HfG-Ulm, quando Rittel tomou posse do seminário, a filosofia da ciência, tornou-se cada vez mais relevante no projecto. Houve uma exploração sistemática das heurísticas que os 
designers estavam de facto a usar. Enquanto o fundamento de Max Bill foi encontrar uma nova unidade estética entre a cultura contemporânea e as formas de objectos produzidos em massa, o design de Maldonado foi equipado com os instrumentos da ciência, a fim de coordenar a decisão, fazendo-a a partir dos centros da indústria. Sob a influência de Rittel, a concepção do designer mudou para alguém que fosse capaz de lidar com a heurística no planeamento e métodos de concepção. De acordo com Krippendorff, podemos dizer que Maldonado, que convidou Rittel para leccionar na HfG, viu nele alguém que contribuiria para a visão científica da Escola, conseguindo alcançar a ligação da ciência ao design, sintetizando e efectivando na prática a ideologia de Maldonado e a Teoria da Informação de Max Bense, vertentes fundamentais para a formação de uma perspectiva computacional no projecto de arquitectura. Embora na HfG-Ulm não houvesse computadores disponíveis, os seus princípios de funcionamento eram conhecidos na Escola, e os resultados comparáveis aos calculados com lápis e papel, como os estudos de algoritmos elaborados nas aulas de Rittel sugerem. Computação foi vista como uma expansão do processo de pensamento, que agora exigia do designer uma compreensão clara de geração de forma, determinação e avaliação. Esta pedagogia científica e tecnologicamente fundada por Rittel, tinha claramente muito pouco em comum com as formas tradicionais e processos de design. A Teoria da Informação, a Cibernética e a Computação tornaram-se temas centrais na HfG, como demonstra o material de arquivo, que se irá analisar no presente artigo.

\section{Base científica no design}

No início do seu ensino, Horst Rittel, e outros membros do corpo docente, debruçaram-se sobre a metodologia científica, sentindo-se compelidos a encontrar matéria dedicada às lógicas de criação de complexidade e redução de complexidade. Rittel, com os seus meios, contrariava a tendência para que as ideologias formais, mais do que qualquer outra coisa, determinassem os projectos na HfG-Ulm. Do reconhecimento da complexidade crescente dos problemas de design, resultou um aumento das informações necessárias que não puderam ser tratadas com técnicas tradicionais do projecto, surgindo a definição crescente do processo de design como um processo informacional.

As ciências de informação para Rittel também foram profundamente utilizadas na catalogação de informação/dados, na esperança de estabelecer uma base científica para o design. O pré-requisito para este catálogo foi em primeiro lugar que o processo de design pudesse ser objectivado e, por isso, padronizado, e, segundo, que certos métodos analíticos e conhecimentos pudessem ser ensinados. As ciências de informação estavam centradas na recolha, análise, armazenamento, recuperação de dados, distribuição e uso da informação, em geral um problema premente, dado que na década de 50 e 60, as ciências e as humanidades encontraram um novo e crescente fluxo de dados. Manteve-se a promessa de uma resposta para o problema através da investigação e do desenvolvimento de metodologias, sistemas e formas de organização adequadas a resolver, tratar e representar os dados. Tal como o ex-aluno da HfGUlm, Gerhard Curdes observou, o pensamento sistemático, ou pensar em sistemas, foi agora elevado à condição de um método: as tarefas de design foram decompostas nos seus componentes, a fim de sintetizálos de novo em novas soluções. O processo de concepção foi analisado em etapas reprodutíveis. Cada tarefa, não importa o quão complexa, é resolvida analiticamente. Deste modo, os problemas complexos puderam ser resolvidos de um modo elementar, sem a necessidade de propôr soluções complexas em detalhe.

Os métodos ensinados por Rittel eram comparáveis aos ensinados a engenheiros e cientistas da computação em escolas americanas, por exemplo, no MIT, naquele tempo. Para Rittel, lançaram-se as fundações vitais para o pensamento preciso e para a compreensão dos processos através das suas palestras sobre lógica, matemática, álgebra, combinatória, metodologia, teoria da ciência, da cibernética e análise matemática operacional. Embora muitos alunos não tivessem o conhecimento necessário para construir sobre essas bases e desenvolvê-las, o prazer particular na dedução lógica, e na geração sistemática de soluções - o núcleo inconfundível da "Metodologia de Ulm" - adveio dos ensinamentos filosóficos que estes experimentaram com Horst Rittel" (CURDES, 2001, p. 37).

No entanto a "cientificação do ensino" espalhou-se e ganhou demasiado controlo sobre o design. O que era problemático nesta abordagem, foi a convicção errada de que os processos, por um lado, eram objectivos, e, por outro, atingissem necessariamente, um novo e bom design. Em Ulm, quase se poderia ter a impressão de que o esquema regulava o pensamento. $O$ desenvolvimento lógico de formas tornou-se tão dominante que o projecto real degradou-se a um ritual de processo mecânico, baseado na lógica.

O desejo de métodos trouxe desacordo na Escola: Maldonado designou de "fetichismo ingénuo do método", embora ele ainda fosse um campeão da metodologia de projecto objectivo e apoiasse um "projecto criativo operatório que recolhesse 
informações classificadas, interpretadas e finalmente, sintetizadas no design" (MALDONADO, 1960).

A aplicação ingénua e directa de teorias científicas em arquitectura começou a tornar-se problemática, com um bom e optimizado desempenho dos sistemas organizados não necessariamente resultado de grandes propostas de design.

Deste modo, o processo e a sua análise cada vez mais assumiam um papel de destaque. Uma e outra vez, a relação entre análise sistemática e a criatividade, junto com a análise e síntese de estruturas do sistema de ensino foi testada ou veementemente discutida. A interacção entre a ciência e design, que inicialmente tinha sido vista como inspiradora, desenvolveu-se numa polarização de "metodólogos "versus "designers".

\section{As aulas de Horst Rittel - Arquivo da HfG- UIm}

\section{Método utilizado}

O método científico utilizado para reconstruir o papel de Horst Rittel na HfG-Ulm, clarificando a abordagem científica que a HfG-Ulm veiculou, através deste mentor, consistiu no cruzamento de três fontes que passaremos a nomear. 1. A recolha de fontes primárias provenientes da visita ao Arquivo HfG-Ulm, baseandose na análise do registo fotográfico dos cadernos com manuscritos originais de algumas disciplinas que Horst Rittel leccionou, tais como Topologia, Análise Matemática Operacional e Metodologia. A leitura, tradução e interpretação dos documentos originais do arquivo da HfG-Ulm, constituiu o núcleo vital do presente investigação, e foi usada de modo a obter informação original que contribuiu para fundamentar a hipótese do trabalho. 2. As fontes bibliográficas relacionadas com a abordagem específica de Horst Rittel, com base nas referências monográficas existentes. 3. Finalmente a utilização de conversas ou entrevistas com intervenientes relevantes desta instituição.

O ensino de Rittel na HfG-Ulm havia sido significativamente informado pelas ideias de sistemas de investigação. $O$ processo de concepção foi analiticamente dissecado nos seus componentes constituintes, para serem resintetizados em design. System-Theory Research investigou o comportamento de sistemas, uma entidade multivariável de mudança ao longo do tempo. As fases temporais do sistema foram mapeadas: o sistema é decomposto nos seus componentes, de modo a estudar as suas relações de causa-efeito. A hipótese partilhada foi que a solução de tarefas complexas não pode ser conseguida de forma intuitiva, mas sim tinha de ser baseada numa dissecação racional do problema. A intenção de Rittel era ensinar métodos e princípios para a detecção e solução de problemas.

O caderno de Metodologia de Rittel (1959-1962) (Figura 4), têm como base a recolha efectuada no arquivo da HfG-Ulm, debruçam-se sobre o que Rittel designou como ciência dos Métodos, ou seja, a Metodologia, em que encontramos uma variedade de informação, que mais uma vez recai nas disciplinas emergentes na época, pela primeira vez introduzidas num curso de design, na Escola da HfG-Ulm, devido à sua intervenção. Nas primeiras abordagens à questão do método, Rittel focou dois polos de acção: por um lado a situação real, por outro a situação pretendida, em que se devem transmitir estratégias já implícitas nos métodos, meios e ferramentas.

Rittel procurou uma alternativa, para passo-a-passo, no processo de design, explorar o design de modelo linear teórico. Embora existam muitas variações no modelo linear, Rittel argumentava que o processo de projecto era dividido em duas fases distintas: definição do problema e resolução de problemas. A definição do problema consistia no solvey process, uma sequência de análise em que o designer determinava todos os elementos do problema e especificava todos os requisitos que uma solução de design com sucesso deveria ter. A solução de problemas era uma sequência de síntese, na qual vários requisitos são combinados e equilibrados uns com os outros, dando origem a uma planta final a ser realizada para a produção. Horst Rittel chamou essas abordagens iniciais 'Sistema de pesquisa de primeira geração", sendo que os métodos propostos por essa geração caracterizavam-se pela sistematização de um processo de três fases - a análise, a síntese e a avaliação - e eram baseadas, principalmente, nas técnicas de Investigação Operacional. Esta abordagem de sistemas de primeira geração implicava uma obrigação de racionalidade, o que significa que se tenta entender o problema como um todo, olhando para as suas consequências, tentando ser racional nesse sentido, antecipando as repercussões de cursos de acções alternativas.

A metodologia de Horst Rittel, denotava uma substituição da capacidade criativa humana pela programação de processos passíveis de uma automatização informática.

$\mathrm{Na}$ Figura 5, é visível a abordagem a temas como a combinatória, sendo que a bibliografia indicada, foram livros específicos nas matérias dadas, tal como "Kombinatorik", ou "Manual de Combinatória" de 
1927, “Introdução à Matemática Aplicada” ou "Os princípios da Técnica Combinatória”.

Figura 4. Caderno de Metodologia, página 2,1959-1962, de Horst Rittel (acima) e Esquema da mesma página (abaixo)

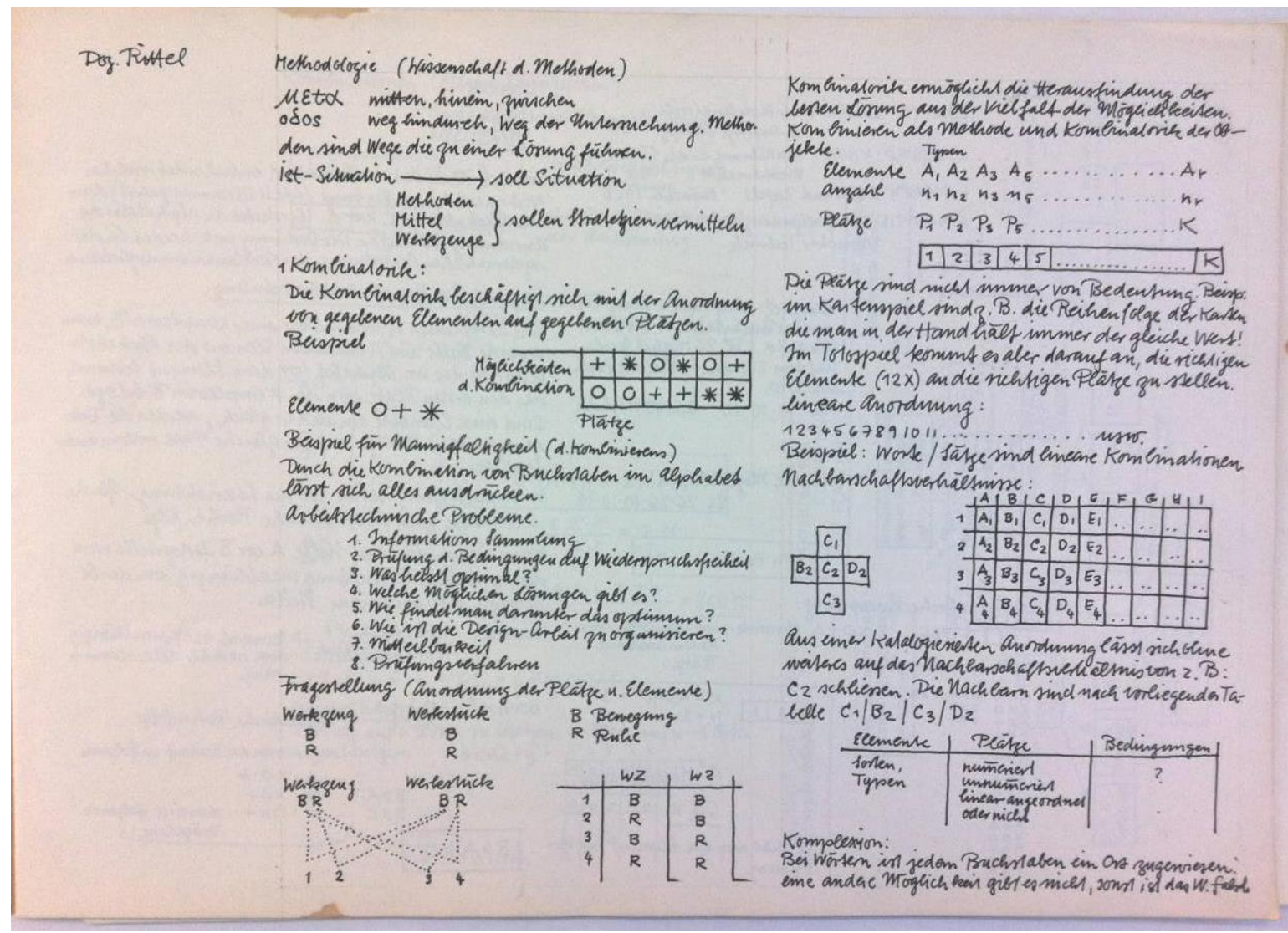

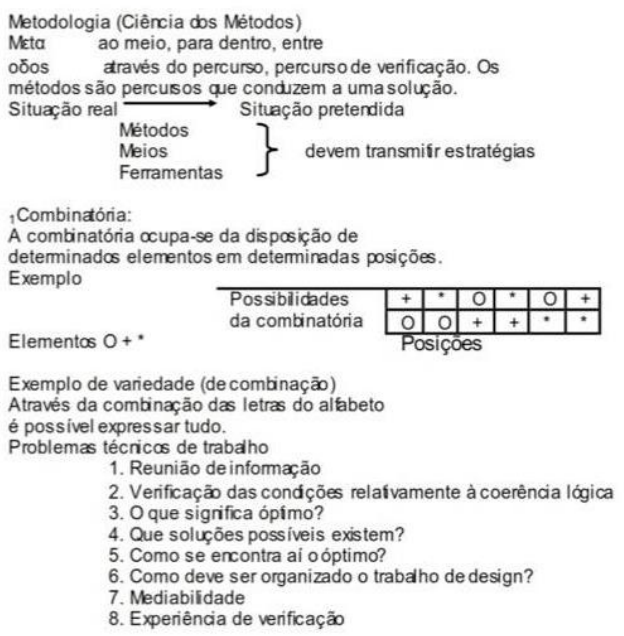

Exemplo de variedade (de combinaçẫo)

Através da combinação das letras do alfabeto

é possivel expressar tudo.

Problemas técricas de trabalho

1. Reuniấo de informậão

2. Verificação das condçcões relafvamente à coerência lógica

3. Oque sigrifica ópímo?

4. Que soluçōes possiveis existem?

5. Como se encontra ai oóptimo?

6. Como deve ser organizado o trabaho de design?

8. Experiência de verificaçẫo

Questão (disposição das posiçōes e dos dementbs)

$$
\begin{aligned}
& \begin{array}{ccl}
\text { Ferramenta } & \text { Peça de trabalho } & \text { M Movimento } \\
\text { M } & M & \text { R Repouso } \\
R & R &
\end{array} \\
& \text { Ferramenta Peça de trabaho } \\
& <\text { desenho }>
\end{aligned}
$$

\begin{tabular}{l|c|c|} 
& FER & $P T$ \\
\hline 1 & $M$ & $M$ \\
2 & $R$ & $M$ \\
3 & $M$ & $R$ \\
4 & $R$ & $R$
\end{tabular}

A combinatória permite encontrar a mehor solução

quanb método e combinatória dos chjectos.

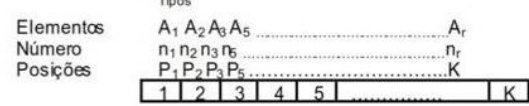

As posições nem sempre são importantes. Ex:

num jogo de cartas, por exemplo, a sequência das cartas

No entanto no totdoto oimportante écolocar os elementos correctos (12x) nas posições certas.

disposiçāo inear.

Exempor...et Relaçōes de proximidade:
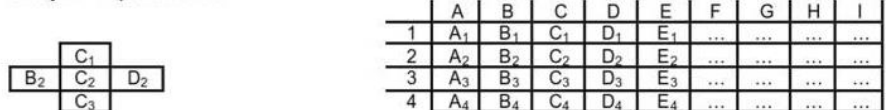

A partir de uma disposição catalogada é, sem mais,

possivel conclur a relação de proximidade de, p. ex.,

C2. Os elementos próximos estão
de acordo com a presente tabela $C_{1}\left|B_{2}\right| C_{3} \mid D_{2}$

\begin{tabular}{l|l|c|} 
Elementos & \multicolumn{1}{|c|}{ Lugares } & Condições \\
\hline Variedades & $\begin{array}{l}\text { numerados } \\
\text { desestruturados } \\
\text { disposição inear } \\
\text { ou não }\end{array}$ & $?$
\end{tabular}

Ligação:

No caso das palavras, a cada letra é atribuida uma posição

não existe outra possibilidade, caso contrário, a palavra está incorrecta.

Fontes: Fotografia da autora no HfG-Archiv Ulm em visita de levantamento de dados em março 2012 (acima) e os autores (abaixo) 
Figura 5. Caderno de Metodologia, página 4,1959/1962, de Horst Rittel (acima) e Esquema da mesma página (abaixo)
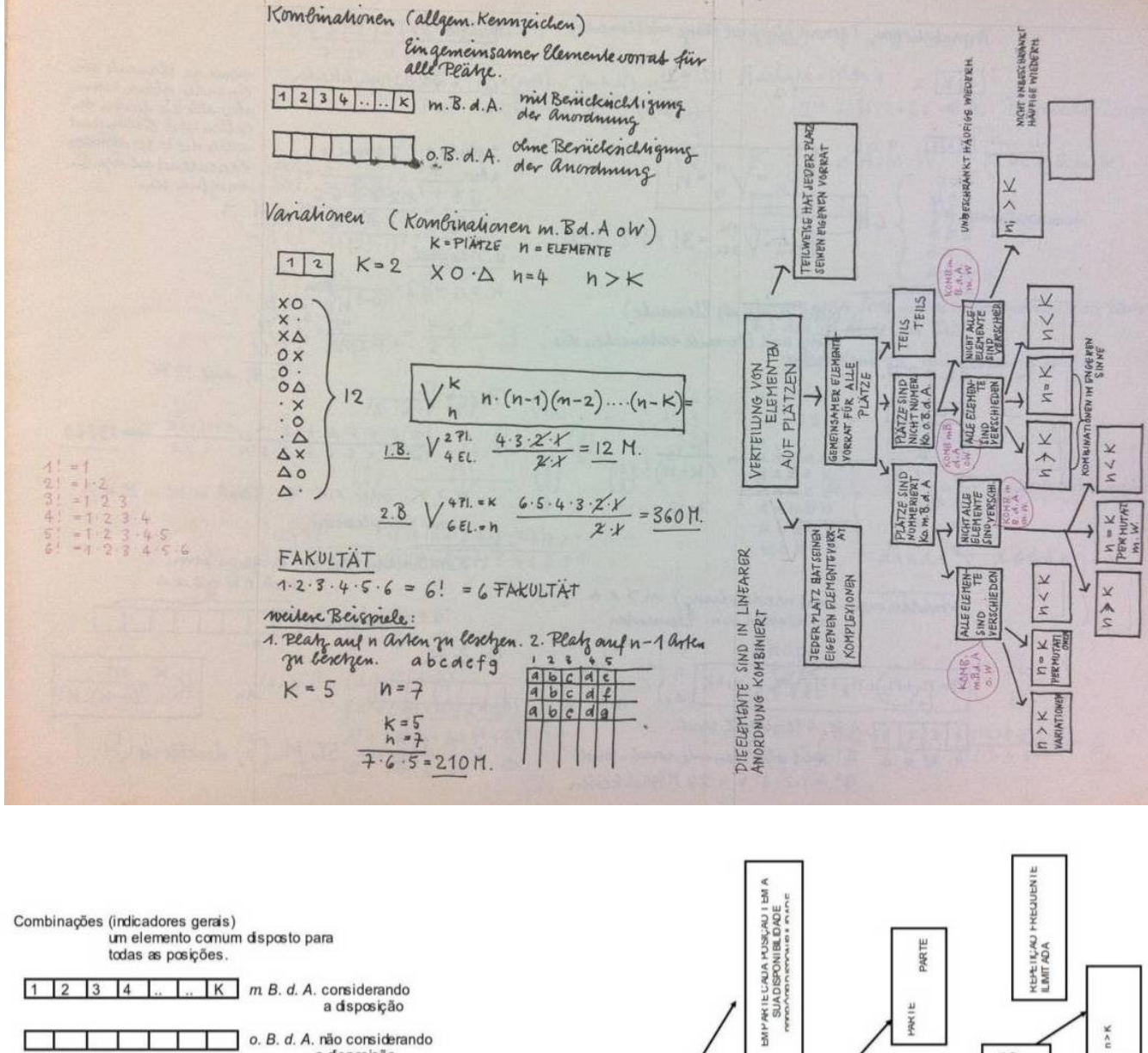

Variaçōes (combinaçōes considerandoa disposiçăo oW)
$K=$ POSIÇOES $n=$ ELEMENTOS

\begin{tabular}{l|lll}
\hline 12 & $K=2 \quad \times 0 \cdot \Delta \quad n=4 \quad n>K$
\end{tabular}

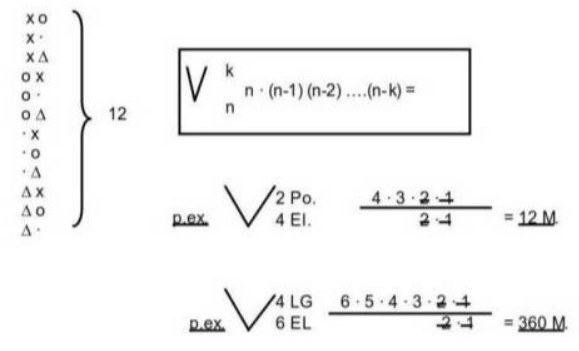

FACULDADE:
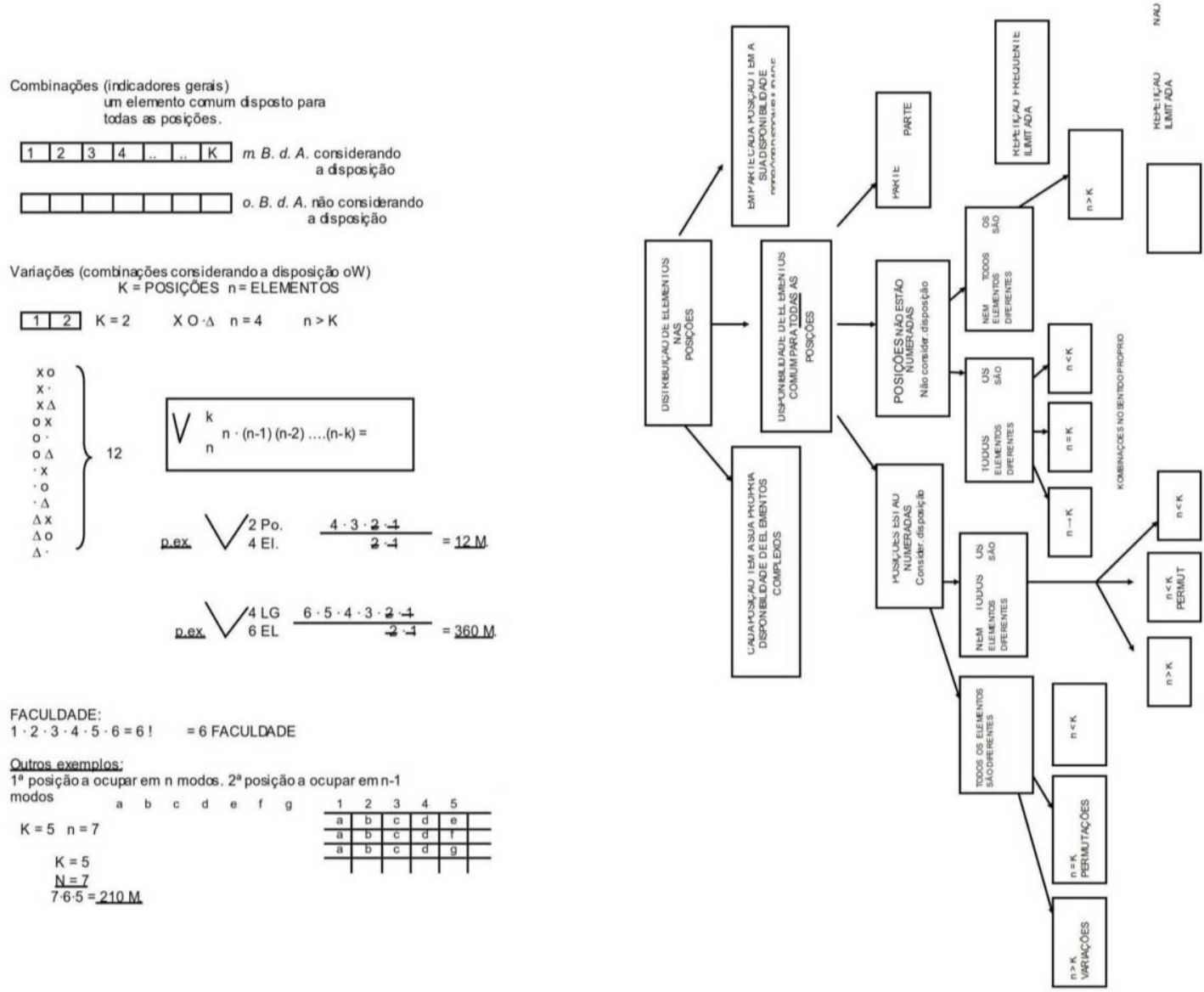

Fontes: Fotografia da autora no HfG-Archiv Ulm em visita de levantamento de dados em março 2012 (acima) e os autores (abaixo) 
Figura 6. Caderno de Metodologia, página 10,1959-1962, de Horst Rittel (acima) e Esquema da mesma página (abaixo)

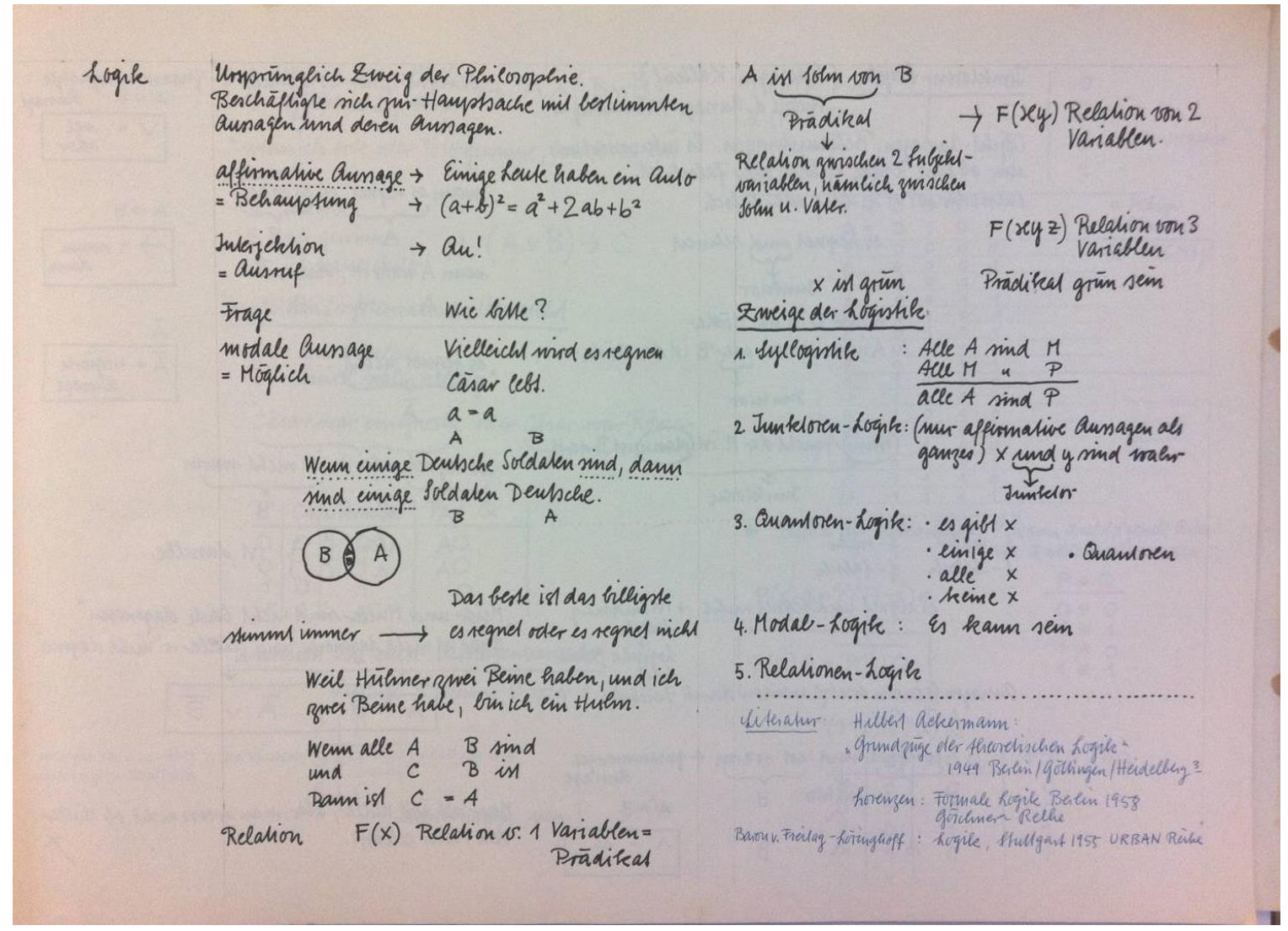

Lógica
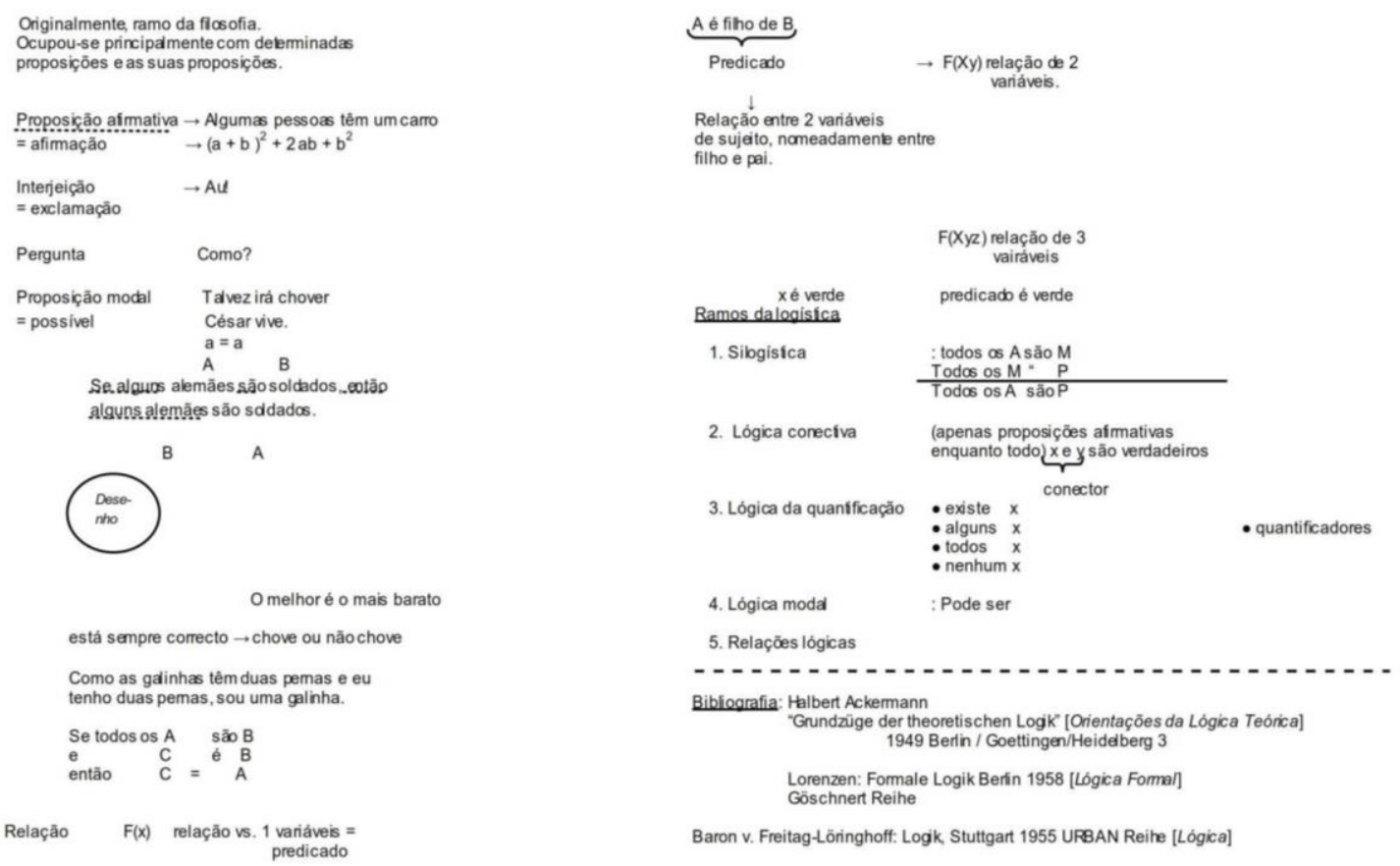

Fontes: Fotografia da autora no HfG-Archiv Ulm em visita de levantamento de dados em março 2012 (acima) e os autores (abaixo) 
Explicita-se como técnica da combinatória: (1) Reunião da Informação; (2) Verificação das condições relativamente à coerência lógica; (3) $\mathrm{O}$ que significa óptimo; (4) Que soluções possíveis existem?; (5) Como se encontra aí o óptimo?; (6) Como deve ser organizado o trabalho de design?; (7) Mediabilidade e (8) Experiência de verificação.

Foi realizado um estudo acerca das variações, combinações possíveis, considerando as posições e os elementos. Podemos observar o quadro da Figura 5, com as várias possibilidades de combinações, esquematizando o processo.

Rittel também abordou a vertente da Lógica (Figura 6), originalmente um ramo da Filosofia. O tema da "lógica" teve dois significados principais: discutiu o uso de raciocínio em estudos normativos, filosóficos e de raciocínio válido. No segundo sentido, a Lógica é discutida principalmente nas disciplinas de Filosofia, Matemática e Ciência da Computação. A Lógica examinava de forma genérica as formas que a argumentação poderia tomar, sendo que algumas das quais dessas formas são válidas e outras são falaciosas.
Na ciência da computação, a Lógica é uma ferramenta indispensável. Por fim, a Lógica também era estudada na teoria da argumentação. Os ramos da logística assinalados, foram o silogismo, a lógica conectiva, a lógica da quantificação e a lógica modal, além das relações lógicas que se analisavam no sentido de, por meio de ilações e iterações lógicas, chegar-se a determinadas conclusões, além da lógica de conectores. $\mathrm{Na}$ disciplina de Análise de Matemática Operacional, de 1959, Rittel focou a noção de estatística, assim como a noção de determinismo e indeterminismo. Com as noções de Pierre Simon Laplace referidas nos apontamentos das aulas de Rittel, consta a seguinte afirmação: LaPlace era da opinião de que tudo é determinado e interpretável através das leis imutáveis da natureza, mas todos os cálculos continham necessária ou inevitavelmente erros, sendo que as leis encontradas apenas permitiam a concepção de prognósticos, mas não de previsões extensas. Caso se parta do princípio de que é necessário ordenar o mundo, então será necessário reflectir sobre o termo "determinabilidade" (Figura 7).

Figura 7. Caderno de Matemática Operacional, página 2, 1959-1961, de Horst Rittel (Esquerda) e Tradução(direita)

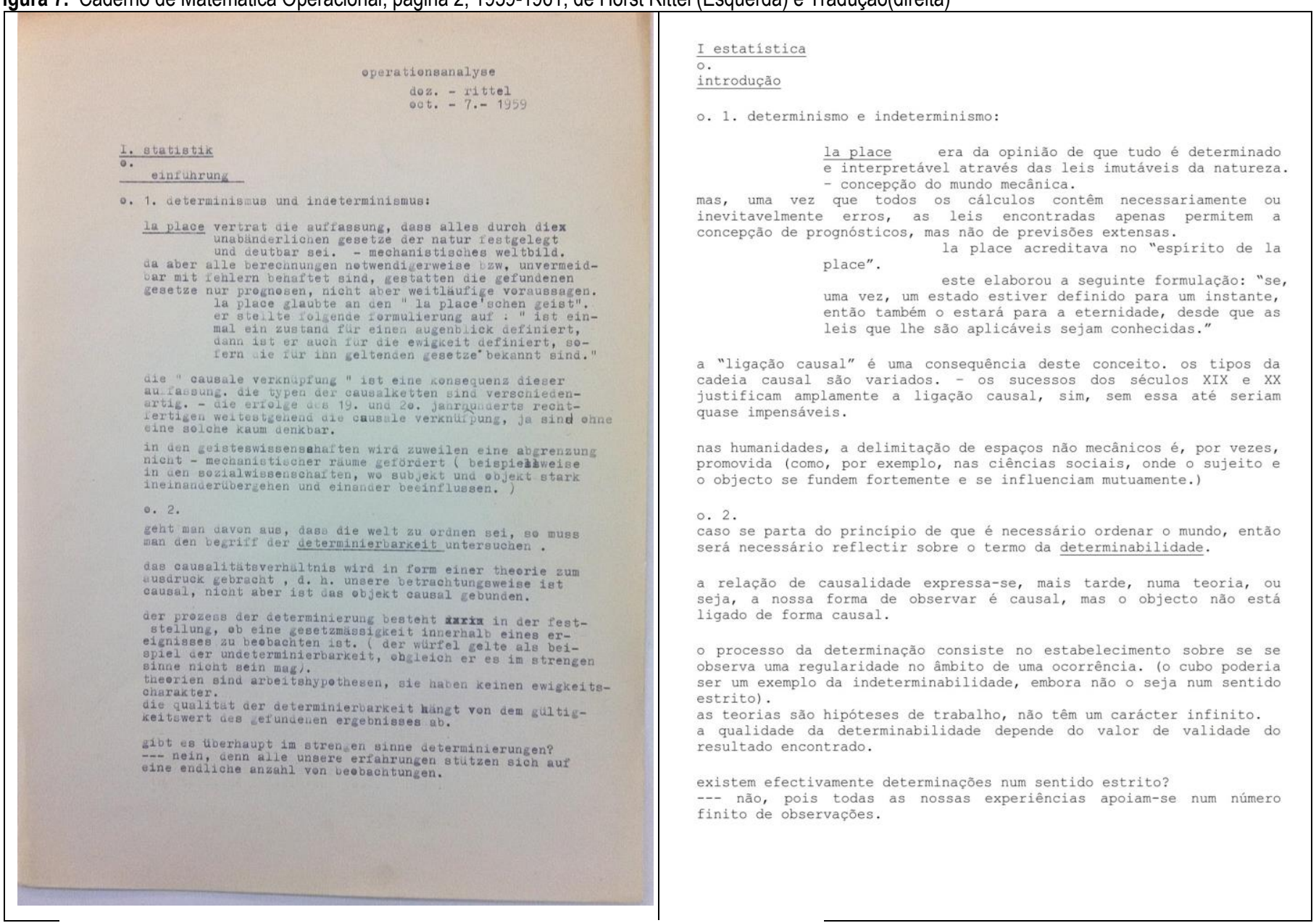

Fontes: Fotografia da autora no HfG-Archiv Ulm em visita de levantamento de dados em março 2012 (esquerda) e os autores (direita) 
Figura 8. Caderno de Matemática Operacional, página 17, 1959-1961, de Horst Rittel (Esquerda) e Tradução(direita)

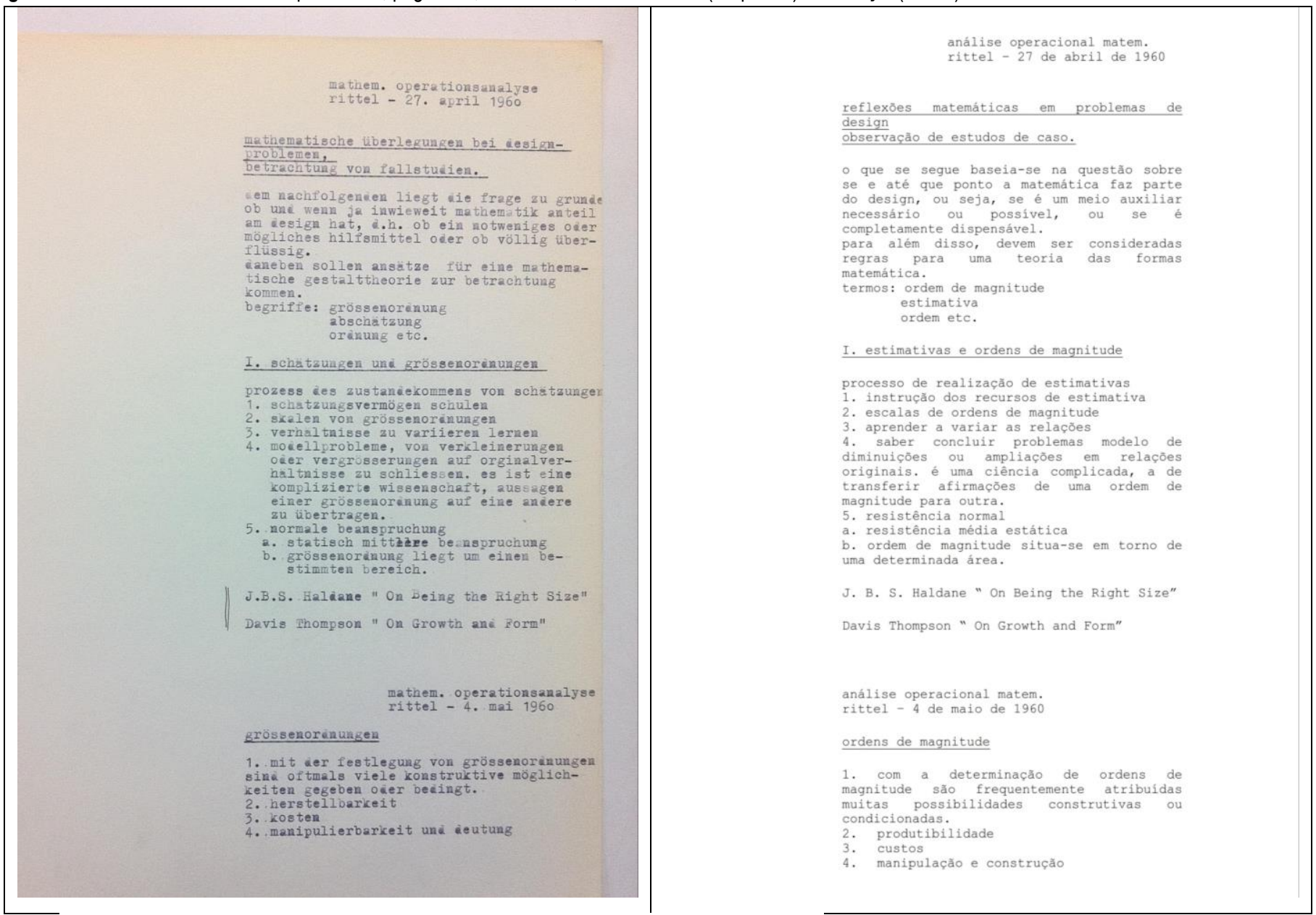

Fontes: Fotografia da autora no HfG-Archiv Ulm em visita de levantamento de dados em março 2012 (esquerda) e os autores (direita)

Esta primeira parte das aulas de Matemática Operacional estão organizadas segundo os seguintes itens 1. Determinismo e Indeterminismo; 2. Determinabilidade; 3. Probabilidade; 4. Objectos da estatística; 5. O porquê da estatística na frequência; 6 . Programa; e finalmente 7. Bibliografia. Uma parcela importante destas aulas de Análise Matemática Operacional (Figura 8), consistiu em várias reflexões matemáticas em problemas de design, e na observação de estudos de caso. Os apontamentos que introduzem esta matéria, começam por explicar que a reflexão que se segue baseia-se na questão sobre se, e até que ponto a matemática faz parte do design, ou seja, se é um meio auxiliar necessário ou possível na área do design. Para além disso deveriam ser consideradas regras para uma teoria das formas matemáticas. Elegem-se três directrizes diferentes, tais como ordem de magnitude, a estimativa, e a ordem. Seguidamente Rittel focava o subtema da forma, estrutura e processos, sendo que a explicação que consta na Figura 9, indica que primeiro deve proceder-se à experiência de criar uma tipologia sistemática ou genealogia. No subtema "forma, estrutura e processos", primeiro deve proceder-se à experiência de criar uma topologia sistemática ou genealogia, sendo que o termo geral de todos estes vocábulos é o termo ordem. Houve um contínuo estudo de probabilidade, que foi desdobrado em vários níveis, regras de adição para o cálculo da probabilidade, probabilidade condicionada, sendo que Rittel nas suas aulas remete também para reflexões matemáticas nos problemas de design, fazendo uma observação de estudos de caso. Entre os termos de "forma", "estrutura" e "processo", a finalidade será a consciencialização da existência de relações entre estes conceitos. Daí, conclui-se, as formas não são apenas geométricas, elas têm também características topológicas. Temas como homomorfismo e isomorfismo também foram temas retratados, assim como a criação de forma e sua reprodutibilidade, como a descrição de formas, estruturas e processos. 
Figura 9. Caderno de Matemática Operacional, página 19, 1959-1961, de Horst Rittel (Esquerda) e Tradução(direita)
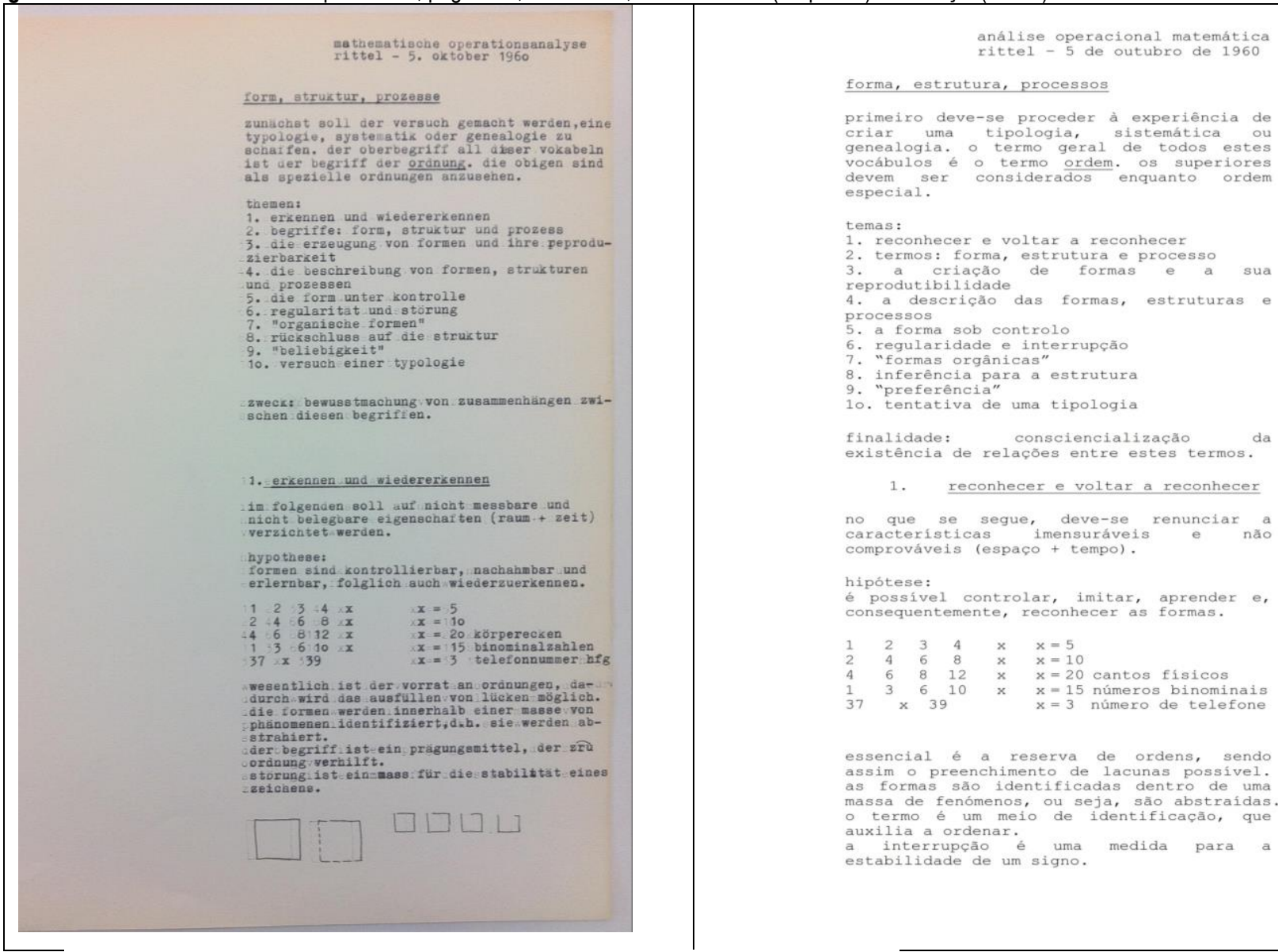

Fontes: Fotografia da autora no HfG-Archiv Ulm em visita de levantamento de dados em março 2012 (esquerda) e os autores (direita)

Embora a matemática ainda fosse vista como a base para o design de produto e planeamento de produto, foi dada menos atenção aos métodos matemáticos finitos e de programação linear, do que a métodos matemáticos que pressupõem a continuidade e conectividade. Isso foi especialmente verdadeiro para a Topologia, que teve grande influência sobre a prática do design na HfG-Ulm, especialmente no contexto das relações espaciais entre os elementos, independentes das suas distâncias reais ou relativas.

O nascimento da disciplina da Topologia remonta ao ano de 1736, quando Leonhard Euler, resolveu matematicamente o problema da Ponte de Königsberg, usando métodos que hoje são vistos como parte da actual teoria dos grafos, também assinalado nas aulas de Horst Rittel. A Topologia foi então definida como a ciência das relações modais de formações espaciais, ou a ciência da relação, a partir da respectiva posição e sequência de pontos, linhas, superfícies, objectos e suas partes ou agregados no espaço, independentemente da sua relação em termos de dimensão -proporção.
No caderno de Topologia (Figura 10), do curso de 1959-1962, as aulas revelam-se muito estruturadas; na aula 1, Rittel descreve que a Topologia se ocupou dos critérios que se maném inalterados quando ocorriam deformações no corpo, dando exemplos, e distinguindo entre Geometria Euclidiana, Geometria Afim, e Geometria Projectiva, dando-se o exemplo das formas inflexíveis tal como a borracha. A literatura sugerida e contemporânea das aulas em questão, outro aspecto por norma presente a cada matéria introduzida por Horst Rittel.

As aulas de Horst Rittel traduziam a construção de uma linguagem da estrutura formal racionalista, daí conformarem uma estrutura programável e algorítmica. A sua organização distinguia desde a função focada na concepção do objecto (produção-exigências), até à função focada no sujeito (fruição-necessidades). Juntamente com outros autores como Christopher Alexander veiculou o processo de computação antes do aparecimento formal e físico do computador. Ainda assim, no final da década de 60, quando potenciaram o computador, usaram-no principalmente em áreas do não-projecto, para calcular e visualizar conjuntos de dados. A solução para um problema parecia ser capaz 
de separar-se dos objectos de observação, ocasionalmente avançando para se tornar um jogo livre de símbolos.

A filosofia positivista do problem solving, com os seus métodos científicos, ou seja, a "resolução de problemas", a análise e síntese de tarefas de projecto em etapas controláveis, proporcionaram não só o design, mas também o processo de design - incluindo a técnica, o material e os aspectos sociais. Grande parte do processo de design foi alocado para $o$ desenvolvimento de diagramas que acompanham os problemas, problemas que se decompunham em subproblemas. Acreditava-se que com o mapeamento do problema, grande parte do problema era resolvido e conseguido. Por esta altura, o processo de resolução de problemas, em vez do resultado arquitectónico actual, tornou-se o mais importante na HfG-Ulm.Pouco sobrou da ideia original que Maldonado tinha tão ansiosamente propagado desde meados dos anos 50, sugerindo que os cientistas fossem os apoiantes e suportes do designer. Pelo contrário, os cientistas como Rittel tornaram-se cada vez mais importantes, tal como o ex-estudante Lindinger relembra que a metodologia de planejamento ganhou tal poder que alguns alunos tornaram-na quase uma religião. Era só uma questão de tempo até que a precisão científica, o sistema e o computador - ainda uma presença distante no horizonte - libertassem o design de todas as suas fraquezas irracionais. (LINDINGER, 1991, p. 11). Sintetizando, Rittel não era um taxonomista que categorizou o mundo, nem um positivista, mas sim um pragmático, cheio de ideias convincentes (KRIPPENDORFF, 2006 p. 312). Rittel, ao ensinar métodos de design, preparou os alunos para um mundo mais complexo, abrindo as possibilidades de investigação empírica. O objectivo seria resolver temas de design complexo com métodos defensáveis.

\section{Figura 10 - Caderno de Topologia, página 2, 1959-1962, de Horst Rittel (Esquerda) e Tradução(direita).}

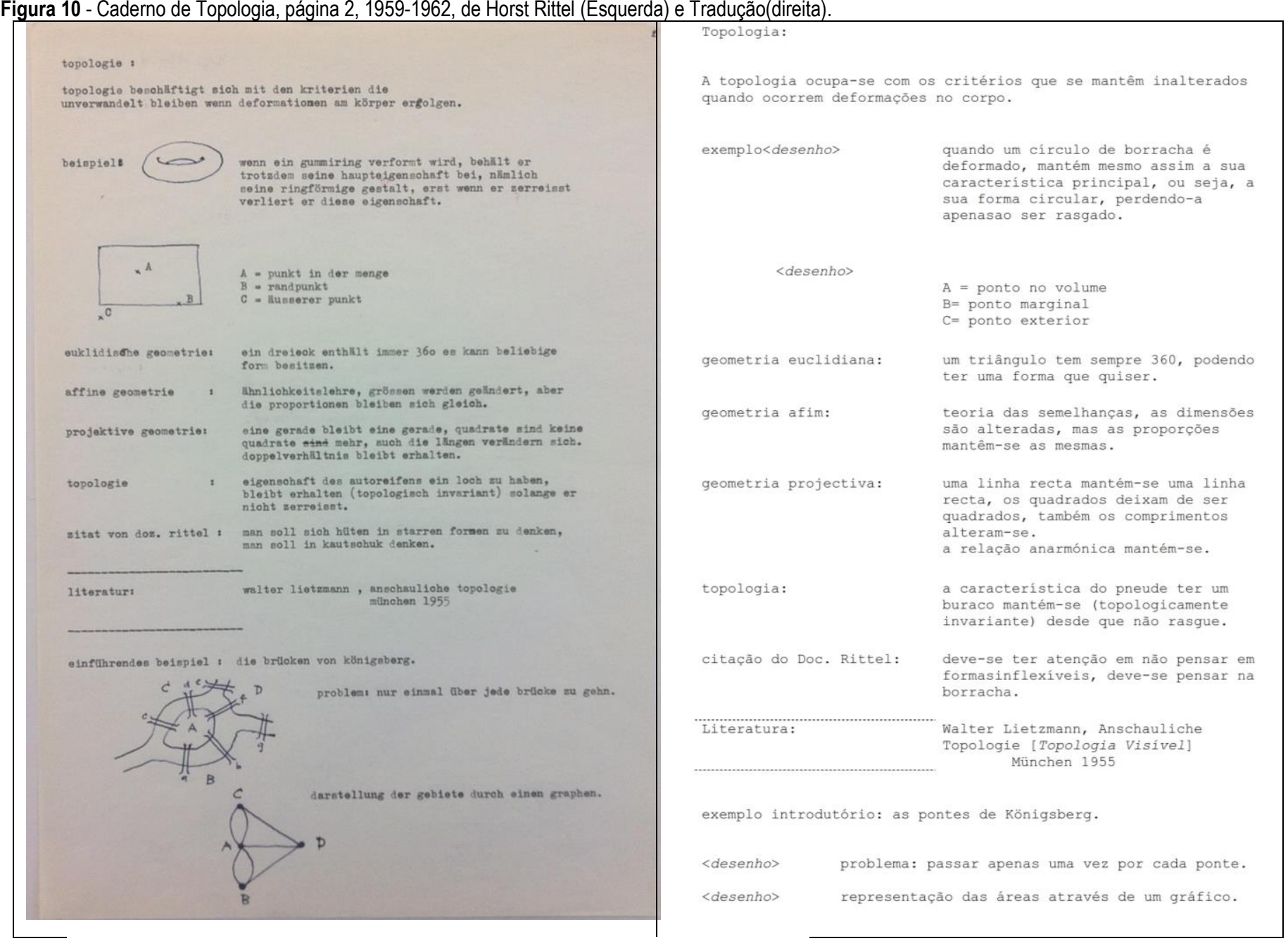

Fontes: Fotografia da autora no HfG-Archiv Ulm em visita de levantamento de dados em março 2012 (esquerda) e os autores (direita) 


\section{Métodos de $2^{\circ}$ Geração de Design (Pós HfG-UIm)}

Rittel continuou a desenvolver todos estes métodos de planeamento depois de deixar HfG-Ulm pelo Departamento de Arquitectura da Universidade da Califórnia, em Berkeley. Aí Rittel moveu-se para além dos métodos de desenho, para formular uma teoria de argumentação estratégica sob a condição de wicked problems. Na verdade, Rittel explica que a génese da sua própria abordagem à metodologia do projecto surgiu quando tentou, por volta da década de 60, aplicar novos métodos de projecto na área de planeamento, e descobriu que obteve resultados satisfatórios. Isso levou-o a reconsiderar os fundamentos da metodologia de design (BUCHANAN, 2009, p. 428).

A noção de wicked problems conduziu Rittel à formulação do que ele designou métodos de segunda geração de design. Esta abordagem assinalou o arranque dos esforços para colocar o design numa base puramente racional que era baseada na epistemologia que Donald Schon, designada de racionalidade técnica.

Crucial para a segunda geração, foi o entendimento do design como um processo argumentativo e deliberativo. A investigação dos wicked problems concentrou-se em encontrar formas de tornar esta deliberação explícita, entendendo a sua estrutura e a sua lógica, suportando-a e fortalecendo o processo, tornando-o mais poderoso e mais controlável.

Em "Dilemmas in a general theory of planning", Horst Rittel definiu os "Wicked Problems" do seguinte modo:

...There is no definitive formulation of a wicked problem; 2. Wicked problems have no stopping rule; 3. Solutions to wicked problems are not true-or-false, but good-or-bad; 4. There is no immediate and no ultimate test of a solution to a wicked problem; 5. Every solution to a wicked problem is a "one-shot operation", because there is no opportunity to learn by trial-and-error, every attempt counts significantly.; 6. Wicked problems do not have an enumerable (or an exhaustively describable) set of potential solutions, nor is there a well-described set of permissible operations that may be incorporated into the plan; 6.Every wicked problem is essentially unique; 7. Every wicked problem can be considered to be a symptom of another problem; 8. Every wicked problem can be considered to be a symptom of another problem; 9. The existence of a discrepancy representing a wicked problem can be explained in numerous ways. The choice of explanation determines the nature of the problem's resolution; 10. The planner has no right to be wrong. (RITTEL, 1973, p.161)

Já em Ulm, Rittel tinha argumentado que as dicotomias que visavam distinguir o sistemático vs intuitivo, e o racional vs o design não racional, eram insustentáveis. Ele interrogava-se antes, em que medida podiam e deviam os processos de design tornar-se explícitos, podendo e devendo tornar-se comunicáveis aos outros, pois apenas podiam ser ensinados processos comunicáveis e processos explicitamente formulados, sendo escrutinados e melhorados de forma crítica.

Esses novos métodos não representavam uma ruptura com os métodos sistemáticos anteriores, mas sim um aprimoramento de suas características, mantendo os princípios de análise e síntese na definição e na solução do problema que o projecto enfrenta. Considerou-se o projecto como um processo composto por fases simultâneas de observação e proposição de soluções. As exigências do utilizador passaram a ter prioridade, e a natureza dos problemas teve especial atenção. O IBIS, Issue Based Information System, foi um sistema de levantamento e organização da informação pertinente de projecto, desenvolvido por Rittel primeiro em papel e depois em computador. Segundo o autor, o sistema $I B I S$ direccionava a identificação, estruturação e a sedimentação das questões levadas pelos grupos que trabalhavam na resolução de problemas, oferecendo informações pertinentes às discussões. Estavam ligados aos sistemas convencionais de documentação, mas também acediam a outras fontes. Os elementos do sistema eram tópicos, problemas questões de facto, posições, argumentos e problemas-modelo (KUNZ; RITTEL, 1970, p. 1).

Conforme o descrito no primeiro relatório publicado por Rittel, os wicked problems eram uma classe de problemas no sistema social que eram mal formulados, onde a informação era confusa, onde havia muitos clientes e tomadores de decisão com muitos sistemas de valores em conflito e onde todos os ramos eram completamente confusos (CHURCHMAN et al., 2006)

Não havia propriamente uma formulação definitiva, mas cada formulação de um wicked problems correspondia à formulação de uma solução. Além disso, este tipo de problemas eram infinitos. As soluções para os wicked problems não eram verdadeiras ou falsas, apenas "boas" ou "más". Para cada problema perverso, havia sempre mais do que uma explicação possível; todo o problema perverso era um sintoma de outro problema de nível superior. 
Para domar um problema perverso, as várias pessoas envolvidas tinham de chegar a acordo sobre metas e acções para alcançá-lo. Isto requeria o conhecimento sobre acções, não apenas factos. Segundo Horst Rittel, o processo de argumentação era a chave e, talvez, o único método de domar problemas perversos. Este processo era político, e segundo Rittel o design é político.

Os seus esforços formaram uma linha em curso de investigação dentro da informática, conhecida como concepção lógica. Rittel depois da sua passagem pela HfG-Ulm, continuou a desenvolver investigação na área do design e a ser significativo na área por duas razões. Primeiro, porque articulou a relação entre a ciência e design, especificamente as limitações dos processos de projecto com base na visão racional do século XIX da ciência. Em segundo lugar, propôs princípios para lidar com estas limitações, como é o caso do projecto argumentativo, aprofundado com a noção dos wicked problems.

\section{A contribuição de Horst Rittel para a abordagem científica ao Projecto no início da era computacional}

Devido à crescente influência dos cientistas que haviam sido convidados para a HfG-Ulm, desde o final da década de 50, especialmente devido ao trabalho de Rittel entre 1958 e 1962, o projecto tornou-se uma ciência, e a arte tornou-se subsidiária. Ao promover esta mudança, Rittel estava principalmente preocupado com o fortalecimento da base científica do processo de projecto na HfG-Ulm, sendo que o ponto de partida, tanto místico quanto ideológico, foi casar arte e ciência, a sua principal motivação. A concepção normal era demasiado orientada para critérios formais e tradicionais de forma. Rittel desejava que todo o conhecimento científico fosse aplicado, sendo levado em consideração na concepção, formação e planeamento, devendo o produto ser desenvolvido a partir dele.

Poder-se-à afirmar que através da abordagem de Horst Rittel foram desenvolvidos métodos inovadores para a cientifização dos métodos de design. Todos os projectos e procedimentos para a produção de formas foram interrogados e tinham que ser justificados ou, na sua falta, seriam julgados como arbitrários, adoptandose a abordagem científica para a integração de métodos sistémicos e objectivos de colheita e processamento de dados, a fim de informar o desenho da solução, tal como sugerem os estudos algorítmicos presentes nos manuscritos das aulas de Rittel, documentados na presente investigação.

Horst Rittel serviu como uma espécie de link para a transferência de conhecimento científico e de engenharia (Teoria da Informação, Investigação Operacional e Cibernética, desenvolvidas durante e após a Segunda Guerra Mundial), para a área do design. A sua ambição foi dominar as tarefas cada vez mais complexas apresentadas pelo design de produto, defendendo-se uma nova cultura filosófica e científica em arquitectura, com o objectivo de substituir a confiança do designer na "intuição" por uma precisão explícita e analítica.

Sob a influência de Rittel o estudante de arquitectura aprendeu a comunicar e treinar as seguintes capacidades e atitudes: a educação filosófica, a lógica da criação e da redução da complexidade, pensando em processos de feedback, o recuo do indivíduo por detrás do trabalho mais importante da equipa como uma organização, a estruturação de preparação de tarefas e caminhos de pesquisa através do trabalho em equipa, e, finalmente, a capacidade de abstracção.

O pensamento sistemático, ou pensar em sistemas, foi agora elevado à condição de um método: as tarefas de design foram decompostas nos seus componentes, a fim de sintetizá-los de novo em novas soluções. O processo de concepção foi analisado em etapas reprodutíveis. A sua força residia no facto de que a decomposição sistemática de uma tarefa em subtarefas, num processo de trabalho a tempo-estruturado, permitiu a tradução fácil para trabalho em equipa subdividido.

Não a forma estética, mas sim o processo de estética tornou-se de grande importância, ao ponto de a solução do processo de concepção de design ser quase irrelevante. Longe de quaisquer concepções tradicionais da arquitectura, as variações foram sistematicamente geradas dentro do espectro de um determinado programa. $\mathrm{O}$ entendimento da forma na HfG mudou decisivamente nesta abordagem, pois a forma não surgiu a partir de um paradigma de forma, mas como o resultado de um processo de solução. Foi a consequência e não o objectivo.

\section{Conclusão}

\section{Computational Design Thinking}

No âmbito específico do Projecto Educacional (ideologia) da HfG-Ulm, pode concluir-se que através da abordagem de Horst Rittel na HfG-Ulm, um pensamento de padrões substituiu um pensamento de 
objectos, e a produção de padrões substituiu a produção de objectos. $\mathrm{O}$ interesse dos artistas e arquitectos, através das suas aulas e direcção na HfGUlm, desenvolveram-se não apenas em elementos únicos isolados e formas inteiras, mas sim com a busca de algoritmos e processos baseados em regras. Os exercícios que envolviam padrões geométricos são exemplos que mostram como os alunos pensavam sobre um conjunto de regras de variação para um determinado módulo geométrico. Subsequentemente, concebiam padrões geométricos, em que o módulo não é uma entidade fixa e repetitiva, mas pelo contrário é um elemento que varia geometricamente em cada instância. Reflectindo uma metodologia científica, a prática de projecto começou a adoptar o conceito de sistemas, onde conjuntos de informações interdependentes eram estruturados para controlar a geração de soluções de design. Nesta abordagem, a ideia de sistemas prevalecia sobre a procura de formas individualizadas e formas acabadas. Estes padrões apresentavam a complexidade das suas possíveis variações, ora através de escalas, ora, ao mesmo tempo, através de várias formas possíveis resultantes da operação de um algoritmo. Embora essas construções fossem desenhadas à mão, já reflectiam um modo de pensamento de design computacional. $\mathrm{O}$ arquitecto já não era o criador de edifícios individuais, mas sim criador de conjuntos de regras que tornaram possível a concepção de arquitecturas infinitas ou generativas. $\mathrm{O}$ arquitecto tornou-se assim o criador de espaço(s) de possibilidade.

Pode concluir-se que na HfG-Ulm empregaram-se algoritmos para gerar o projecto de arquitectura/design, o que significou identificar claramente o problema, descodificando-o e adaptando-o. Abordou-se a questão de "desenhar as questões de projecto", as "regras geradoras da forma", em vez de desenhar a forma propriamente, assimilando e debatendo o emprego de algoritmos. Os processos algorítmicos utilizados na HfG-Ulm estavam mais relacionados com procedimentos lógico-matemáticos utilizados no processo de projecto, do que com o uso da máquina propriamente dito.

Percebeu-se então que a metodologia desenvolvida na HfG-Ulm apresentava fortes paralelismos e similaridade de intenções com a metodologia de processo de design paramétrico/algorítmico. Alguns aspectos fundamentais desta metodologia permitiramnos fazer esta analogia: a noção de domínio da forma através da interrelação geométrica, tornando possível explorar variações do projecto e outras soluções espaciais; a decomposição do objecto em partes ou componentes que podiam ser descritas através das regras; e finalmente a intenção de explorar novas formas baseadas na lógica; o arquitecto/designer partia das regras que regiam as formas, em detrimento das formas estabelecidas, dominando as regras do sistema, mas não as formas geradas.

Ao longo de muitos anos de ensino de design computacional, tem-se compreendido que o principal desafio não será residir na mistura de técnicas de design computacional, mas em vez disso, aculturar um modo de design thinking (MENGES; AHLQUIST, 2011). Concluiu-se que na HfG-Ulm buscaram-se precisamente lógicas internas à própria computação como fonte primordial para a criação de novos conceitos, explorando-se um domínio mais próximo do designado design thinking, do que propriamente o das técnicas de design computacional. Devido a esse factor atribuimos radicalidade e inovação à pedagogia Ulminiana, protagonizada de forma relevante e fulcral pelo docente analisado, Horst Rittel.

\section{Agradecimentos}

Agradecemos ao Arquivo da HfG-Ulm (The HfG Ulm School of Design, http://www.hfg-archiv.ulm.de/english/the hfg ulm/), e à Fundação da Ciência e Tecnologia, que apoiou esta investigação.

\section{Referências}

BUCHANAN, R. Thinking about Design: A Historical Perspective. In: MEIJERS A. The Philosophy of Technology and the Engineering Sciences, Elsevier, 2009. p. 409-453.

CHURCHMAN, C. W.; PROTZEN, J. P.; WEBBER, M. M., KROGH, D. In Memoriam: Horst W. J. Rittel. Design Issues, v. 23, n. 1, p. 89-91, 2007. http://www.jstor.org/stable/25224093

CURDES, G. Die Abteilung Bauen an der hfg Ulm: eine Reflexion zur Entwicklung, Lehre und Programmatik. Stuttgart: Club off Ulm, 2001. 
FRAMPTON, K. Apropos Ulm: Curriculum and Critical Theory. Oppositions, v. 3, p. 17-36, 1974.

FRAMPTON, K. Apropos Ulm: Curriculum and Critical Theory. In: Labour, Work and Architecture, p. 44-63, London: Phaidon Press, 2002 apud FRAMPTON, K. Apropos Ulm: Curriculum and Critical Theory. Oppositions, v. 3, p. 1736, 1974.

KRIPPENDORFF, K. The semantic turn: A new foundation for design. Boca Raton: CRC Press'Taylor \& Francis Group, 2006.

KUNZ, W.; RITTEL, H. W. Issues as elements of information systems. In Working Paper 131. Berkeley, CA: Institute of Urban and Regional Development, University of California, 1970. Disponível em: http://www.cc.gatech.edu/ ellendo/rittel/rittel-issues.pdf.

LINDINGER, H. Ulm design: the morality of objects. Hochschule fr Gestaltung Ulm, 1953-1958. Cambridge: MIT Press, 1991.

MALDONADO, T. Design Education. Form, v. 12, p. 36-39, 1960.

MALDONADO, T. Looking back at Ulm. In: LINDINGER, H. Ulm design: the morality of objects. Cambridge: MIT Press, 1991.

MENGES, A.; AHLQUIST, S. Computational Design Thinking: Computation Design Thinking. Chichester: John Wiley \& Sons, 2011

PROTZEN, J. P; HARRIS, D. J. The Universe of Design: Horst Rittel's Theories of Design and Planning. New York: Routledge, 2010.

RITTEL, H. W.; WEBBER, M. M.. Dilemmas in a general theory of planning. Policy Sciences, v. 4, n. 2, p. $155-169 ; 1973$.

ROCKER, I. Emerging Structures: Information Aesthetics and Architectures of the Digital Medium. 2010. Tese (Doutorado) - Princeton University, Princeton, 2010.

SPITZ, R. Hfg Ulm: the view behind the foreground: the political history of the Ulm School of Design, 1953-1968. Stuttgart: Edition Axel Menges, 2002.

\section{${ }^{1}$ Isa Clara Neves}

Mestre de Arquitectura. Doutoranda em Teoria e História da Arquitectura pela FAUL. Membro colaborador do CIAUD (Centro de investigação em Arquitetura, Urbanismo e Design da FAUL). Rua Sá Nogueira, 1349-055 Lisboa, Portugal 